\title{
Una función con móbiles y tentetiesos de Marcos Carías o la tensión entre modernidad y posmodernidad en la escritura narrativa
}

Héctor M. Leyva*

\section{RESUMEN}

La ponencia ofrece un análisis interpretativo de la novela Una función con móbiles y tentesiesos (1981) del hondureño Marcos Carías. El análisis procede mediante una descripción semiótica de los componentes textuales (discurso y estructura), los cuales discute con referencia a los estudios críticos de la obra (Arias, A.; Bermúdez, H.; Torres, C.; Umaña, H.), y especialmente con referencia al concepto de 'novelas de lenguaje' de Ángela Dellpiane y las características de la estética posmoderna que plantea Frederic Jameson. El argumento principal sostiene que si bien la novela abre las puertas a los discursos que atraviesan la sociedad para ofrecer una imagen fragmentada, multívoca y fluida de la misma (en la línea de la estética posmoderna), tal modo de representación no supone una renuncia a la intelección o a la construcción de sentido por parte del autor sino que viene a ser concreción de las pretensiones vanguardistas de una novela total que fuera capaz de construir imágenes que dieran cuenta de la complejidad de lo real (en la tradición de la estética y el proyecto de conocimiento de la modernidad).

En este sentido, la ponencia enfoca la tensión en la escritura narrativa (como un dilema típico entre los intelectuales y artistas de la década de 1980) entre la herencia de la modernidad, que confiaba en la intelección para la conducción del mundo, y las tendencias de la posmodernidad hacia la disolución del sujeto y la razón en el acontecer social.

Palabras clave: novela, vanguardia, modernidad, posmodernidad, pensamiento crítico

\section{ABSTRACT}

The paper offers an interpretive analysis of the novel $A$ function with mobiles and tentesiesos (1981) by the Honduran Marcos Carias. The analysis proceeds through a semiotic description of textual components (discourse structure), which are

\footnotetext{
* Universidad Nacional Autónoma de Honduras, Facultad de Humanidades y Artes, Escuela de Letras hleyva90@hotmail.com
} 
discussed with reference to critical reviews of the work (Arias, A., Bermudez, $H_{\text {., }}$ Torres, C., Umana, H.), and specially with reference to the "concept of 'language novels"' by Angela Dellpiane and the characteristics of postmodern aesthetics that Frederic Jameson raises. The main argument holds that although the novel opens up the discourse that cross the society to give a fragmented and fluid image (in line with the postmodern aesthetic), that way of representation doesn't suppose a waiver to the intention or to the construction of meaning by the author, but which comes to be a realization of the vanguard claims of a total novel that was able to construct images that realized the complexity of reality (in the tradition of aesthetics and the draft knowledge of modernity).

In this sense, the paper focuses on the tension in the narrative writing (as a typical dilemma between intellectuals and artists of the decade of 1980) between the heritage of modernity, which relied on the insight to drive the world, and trends of the postmodernism to the dissolution of the subject and reason into social befall.

Key words: novel, vanguard, modernity, postmodernism, critical thinking 


\section{INTRODUCCIÓN}

En 1980 Marcos Carías publicó Una función con móbiles y tentetiesos una novela que fue celebrada como una de las más ambiciosas e importantes de Honduras por críticos del país como Hernán Antonio Bermúdez, Helen Umaña y Claudia Torres, y de otros países como Arturo Arias. Este último crítico de origen guatemalteco y profesor en la Universidad de Texas en Austin escribió: "efectivamente es la novela más ambiciosa que se ha escrito en Honduras pero es también algo más que eso: es la más divertida y es la mejor novela que se ha escrito en Honduras, una de las mejores que se han escrito en Centroamérica y una de las grandes novelas latinoamericanas de este siglo" (185).

A pesar de estos elogios la novela ha tenido y tiene pocos lectores (entre los más entusiastas los mismos escritores) cuando por sus méritos bien podría tenerlos a millares dentro y fuera del país. Aquí quiere volverse sobre esta novela para promover su lectura y para intentar comprender las bases de su estética. No precisamente explicar el que un texto artístico que logra ser una obra maestra no encuentre lectores, pero sí llamar la atención hacia ese balance contradictorio que se haya en el que quizás sea el experimento narrativo más osado de la literatura hondureña. Hacer ver esa situación paradójica en la que el impulso por alcanzar la comprensión intelectiva de la realidad en la obra de arte (impulso típico de las vanguardias artísticas heredero de la tradición de la modernidad), conduce a la producción de una imagen tan rica, heterogénea y compleja que tiende a diluirse como el sujeto mismo en esa realidad (como en los estilos en boga de la posmodernidad).

\section{DISCUSIÓN}

Puede observarse que para críticos como Hernán Antonio Bermúdez o Helen Umaña la novela es típicamente moderna por su afán de totalidad, pues encuentran que intenta atrapar a través de los flujos discursivos de múltiples personajes la vida de la ciudad de Tegucigalpa. Bermúdez compara la relación de esta novela con su ciudad como la del Ulises de Joyce con Dublín, al sostener -parafraseando al escritor irlandés- que si alguna vez desapareciera de la faz de la tierra podría ser reconstruida a partir de esta novela por cuanto viene a ser una summa literaria de ese microcosmos (134). Para Helen Umaña la novela ofrece "un verdadero mural totalizador de la vida tegucigal pense", "una ciudad que nunca antes había alcanzado tal grado de verbalización", y esto conseguido mediante "la captación de una realidad formada de infinitas vidas y voces comunes y corrientes que se cruzan y se superponen" (254). 
En la novela -escribió Lukacs siguiendo a Hegel- el autor de la modernidad intenta "abarcar la totalidad extensiva de la vida", renovar la epopeya en "un tiempo para el cual la inmanencia del sentido de la vida se ha vuelto un problema" (1962: 52). Siguiendo a Marx, Lukacs iba a destacar el objetivo de la novela de ensayar en el plano del arte la comprensión de la experiencia humana de la historia, "procurar la vivencia de los móviles sociales e individuales por los que los hombres pensaron, sintieron y actuaron precisamente del modo en que ocurrió en la realidad histórica" (1966: 44). Un ensayo de "plasmación poética" añadiría Lukacs que muchas veces se consigue mejor prestando atención más que a los grandes acontecimientos históricos a las vivencias de las personas comunes y corrientes y a los sucesos "aparentemente insignificantes" (1966: 44).

Otros críticos de la novela, consideran que responde más bien a una estética posmoderna sobre todo por la multiplicidad de voces que desestructuran la voz del narrador tradicional (aquella voz monótona que presentaba, organizaba y explicaba la acción en la novela realista y racionalista) y por recurrir a una representación fragmentaria de la realidad (en tanto que en lugar de una visión de unidad lo que la novela ofrece son multitudes de fragmentos de situaciones, acciones, de conversaciones etc.). Para Arias la polifonía es una "función posmoderna" "que busca disolver el texto". Los personajes y la trama pierden importancia, la novela no busca construir un sentido sino que se cierra sobre su ambigüedad y opacidad: "Todo es voces", "una ciudad construida de palabras" (188-190). Para Claudia Torres el afán de la novela no es totalizador sino "desintegrador", "ofrece una multiplicidad de perspectivas", "no un conglomerado totalizado sino un mosaico diverso". "El autor no pretende darnos una reflexión profunda, digerida y comentada, al contrario nos presenta una especie de colección de fotografías que nosotros como lectores tenemos que analizar" (4-5).

Desde nuestro punto de vista, la novela arranca como un proyecto típicamente moderno que puede comprenderse desde el ángulo del vanguardismo literario (que reacciona contra las formas tradicionales de la narración buscando alcanzar formas de representación más ricas y complejas de la realidad) pero que al avanzar en esta dirección llega a confundirse con las propuestas posmodernas (explotando las posibilidades de autorreferencialidad del lenguaje y de la fragmentación como estrategia de captación del mundo).

Matei Calinescu ha señalado que lo que los vanguardistas de las distintas disciplinas artísticas buscaban era deshacerse de las constricciones formales de la tradición para disfrutar de la más plena libertad para explorar los límites de la creatividad y de lo completamente nuevo. Y esto como una forma de llevar el 
espíritu de la crítica social al dominio de las formas artísticas, en cuanto que revolucionar el arte era una forma de revolucionar la vida (112). Una idea central del proyecto moderno que heredaron las vanguardias -subraya Calinescu- es la del progreso: las vanguardias artísticas no sólo se sienten participar de esta teleología (como forma de entender el sentido de la historia) y de este movimiento (como forma optimista de vivir el acontecer) sino que consideran que son su avanzada más arriesgada, la que abre las brechas y descubre lo nuevo.

En la Honduras de la década de 1970, donde apenas se salía de una sociedad rural y se aceleraban los procesos de industrialización y urbanización, debió vivirse con particular intensidad (con la intensidad que puede suponer la conciencia de vivir una dramática anacronía) la necesidad de renovar enteramente la vida social. El imperativo de revolucionar la sociedad (que cobraba auge en todo el continente desde el triunfo de la Revolución cubana) se encontraba armónicamente con el de revolucionar la literatura (anclada en Honduras en los modelos del realismo regionalista en unos años en que los experimentos narrativos se hallaban también en auge con los autores del boom latinoamericano). De modo que la empresa de Una función, su gesto ambicioso y enérgico de renovar la tecnología narrativa, pudo no resultar descabellado, sino necesario en esa sociedad y en ese momento.

Arias considera que una función lleva su revuelta formal más allá del desembarazamiento de los moldes de la narrativa regionalista local. Desde su punto de vista, la risa que convoca llega a confrontar los modelos narrativos eurocéntricos en que pudo haberse inspirado. Observa, por ejemplo, la parodia que hace de técnicas vanguardistas consagradas como la del fluir de conciencia de estirpe joyceana (pues logra pasajes humorísticos al habilitar monólogos interiores de estrafalarios personajes locales). "Centroamérica -dice Arturo Arias- se permite por medio de este texto burlarse de la tradición occidental" (191).

Ciertamente es posible que la experimentación formal y el humor hayan podido conducir a rebatir a "Occidente" (tan distante como ambiguo), lo cual no niega plausibilidad, sin embargo, al hecho de que tal iniciativa pudo haber arrancado de la confrontación en el ámbito más próximo del autor con unas estrategias y unas temáticas narrativas estrechas y desfasadas para sus propósitos. En cuanto al humor, no puede dejar de observarse su importancia en Una función y la paradoja de estar ante una obra maestra que es también una obra humorística.

En esta novela, en efecto, se hace entrar con humor y con astucia compositiva el universo verbal de la ciudad. El autor consigue instalar en el corazón de la maquinaria narrativa la risa (la propia y la de la ciudad) que permite incorporar los 
discursos más dispares de las más distintas procedencias (de la alta y la baja sociedad, de los intelectuales y los mendigos, de las señoritas y las prostitutas, del buen burgués y de la sirvienta, de los periodistas, las profesoras y los militares, de los idealistas y los cínicos, de los templos y del mercado, etc.). Discursos que al ser sorprendidos en su más nítida cotidianidad, exhiben su candidez, su desfachatez 0 su absurdidad. La risa en uno de sus sentidos es gozo de vivir (lo que permite apoyar una cierta estética) mientras en otro (más importante para la novela) es una operación de la inteligencia que descubre lo ilógico, lo tonto o inconveniente en los actos o pensamientos de las personas. En la novela se demuestra que la risa opera en todo momento como una fuerza disociadora que rebaja todo lo que se tiene por elevado o por norma (incluidos los fundamentos del poder y de la autoridad) y hace saltar al primer plano la banalidad o la desgracia de los esfuerzos humanos.

Detrás del discurrir aparentemente desenfadado de la novela, entonces, se advierte esa inteligencia que la está orquestando, una inteligencia que en un sentido es la del autor que disfruta con las ocurrencias de su creación verbal, y que en otro es la de la modernidad (como órgano de la razón que juzga los actos humanos respecto de la lógica, la moral y el saber, y que por eso es capaz de las obras más elevadas tanto como de los ingenios más irreverentes). Importante para comprender la novela es también su estrategia compositiva (no ajena del todo al propósito humorístico) que despliega una multitud aparentemente inconexa de situaciones (como en un enorme rompecabezas del que no se sabe por dónde empezar). De nuevo lo central es la inteligencia pero sorprendida en problemas 0 provocándolos pues la conciencia de unidad sólo es posible por el arte de las asociaciones múltiples.

La composición a partir de fragmentos cumple en la novela la función del collage en el arte vanguardista, en cuanto que yuxtapone los distintos ángulos y los distintos elementos y apariencias con que un objeto (en este caso la ciudad) se ofrece a la percepción. Para el cubismo, señala Mario De Micheli el collage surge como un intento por fijar en la tela todas las facetas, todos los momentos del objeto y su variedad ininterrumpida de apariencias y de signos con una intuición esencial (211). En este sentido el collage es una forma de representación que busca atrapar la unidad de un objeto complejo (con lo cual es un esfuerzo de intelección) y no como se entiende en el arte posmoderno como el resultado de una pérdida del sentido de realidad.

Para Jean Francois Lyotard el arte de vanguardia sigue siendo moderno aun en sus imágenes fragmentadas o no figurativas por esta aspiración al conocimiento. Incluso en la máxima fragmentación podría hallarse la "estética de lo sublime" de 
que habló Kant como expresión de la más intensa y contradictoria visión de la totalidad (71). Para Frederic Jameson algo distintivo de la posmodernidad es la obsolescencia del artista como sujeto de conocimiento en cuanto que ha perdido (en el contexto de la bancarrota de la alta cultura y de la era de la cultura de masas) su capacidad (o su pretensión) de comprender las múltiples articulaciones temporales y de ofrecer una representación coherente de su experiencia. De ahí que las obras del artista posmoderno no puedan ofrecer otra cosa que un apilamiento azaroso y heterogéneo de fragmentos (209).

Los principios compositivos del collage que organizan el cuerpo de la novela pueden apreciarse en cualquiera de sus partes. Por ejemplo en las primeras líneas de la novela se superponen distintos personajes y situaciones. Dice:

"Ven a David: Está a medio camino y hoy es su cumpleaños. Medio cuerpo debajo de la puerta, un pie hacia delante, una sonrisa dirigida al tendido y el trago a la altura del pecho. La del rincón, en primer plano, es Amapola. Amapola no es precisamente una muchacha; las mangas en escorzo y los aros que relumbran por detrás le corresponden al cortejo de esa noche. No se sintió el teléfono. Estadísticas personales revelan que en un $63 \%$ de ocasiones sentía el teléfono antes de producirse la llamada. Dijo el doctor: "las personas tensas como usted". Julia atendió al aparato. Usted, que apenas se sienta a la mesa pone las manos en ademán de levantarse, si usted. Que te acuestas a dormir la siesta sin desentumecer los pies. Julia estaba al lado del teléfono y lo pudo recoger al primer rebote. Estaba ahi porque esperaba comunicación con Víctor Hugo. Estaba, se explica Julia, junto al teléfono porque había dejado el trago en la mesita... La voz. Soy yo. No me gustó esa voz. No me gustan nunca los olores del teléfono. ¿De quién?... Y me iba a enderezar las medias, oyó... huelen, una mueca, son las voces que se destilaron por los vericuetos. Al arreglarte las medias tuviste que palparte el muslo y pensarías en él. Ajú..."(pp3-4).

Las frases aquí no pueden leerse como líneas consecutivas sino como fragmentos dispersos, hace falta reconstruir. La escritura como aproximación desde distintos ángulos (asociaciones) a una misma situación y la lectura como propuesta de una unidad de sentido que no viene explícitamente dada en el texto. No predomina un punto de vista, se yuxtaponen la voz del narrador, la de David al teléfono, la de Julia, la del doctor, y se traslapan las situaciones (David viendo a Amapola y, al otro lado del teléfono Julia componiéndose nerviosa las medias). El lector tiene que atar cabos y arriesgar hipótesis. Sólo 25 páginas más adelante se sabrá que Amapola es un personaje más en la fiesta de cumpleaños de David: 
"- Esta Amapola no es precisamente un bello botón de primavera pero tiene sensibilidad, tiene cultura, inteligencia y un ustedes ya me entienden que, uy, perdone padre.

- Ingeniero, ingeniero"(29).

Gillo Dorfles encuentra que a pesar de su fragmentación y de las demás estrategias que despliega el arte vanguardista, éste continúa ligado a la tradición realista y racionalista que viene desde el Renacimiento por su aspiración a la imagen. Echadas por tierra las normas del arte como reflejo de la realidad (que ofrecía visiones estables y unitarias) ahora, aun descomponiendo, alterando 0 trascendiendo esas visiones (comparables en las nuevas obras a las de trozos de espejos rotos, a las de la abstracción pura, a las de los sueños o las alucinaciones) el vanguardismo continúa en el empeño (que Dorfles considera más fundamental) de lograr en el arte configuraciones que expresen la percepción de la experiencia humana del tiempo y la sociedad, (una experiencia más dinámica, confusa y ambigua en la actualidad que nunca antes) (17-30).

El arte señala Dorfles, es una "experiencia cognoscitiva" que media "entre el sujeto y el ambiente circundante, entre el objeto percibido y el sujeto que percibe". "El individuo establecería siempre ciertas ilaciones en torno al mundo en que vive, derivadas de prestar una determinada significación a todo estímulo ambiental" (26). En la actualidad, añade Dorfles, "la facultad de pensar" y la "actividad artística" "están sometidas a una continua proliferación autónoma, en la que el elemento unitario está intencionalmente escindido, roto, fragmentado, con el fin preciso de crear unidades nuevas, nuevos organismos, nuevos niveles de perceptividad" (27). Para Dorfles la mente creadora percibe y manipula los estímulos del ambiente y la experiencia persiguiendo su comprensión, intentando reconocer "la presencia de una estructura" y la de elaborar su "significación" (27-28).Para Dorfles, entonces, el artista está creando obras que organizan percepciones y permiten reconocer estructuras en el mundo. Importante en el caso de Una función es la similitud que el autor establece con los móviles de Calder. En una entrevista personal el autor describió la construcción de la novela como un collage dinámico: "La estructura es la de un collage y la dinámica, ya que es un collage que se mueve -móbiles, estilo Calder..." (Carías, M.: 1984).

Los móviles suelen construirse haciendo colgar con hilos pedazos de distintos materiales que al más mínimo soplo se mueven. Esto supone que en la visión del autor, la novela está construida como un artefacto que permite visualizar y apreciar el movimiento de personajes y situaciones. 
"...luego -añade el autor- los personajes son tentetiesos, la palabra que resultó menos difícil de lo que me imaginé, cuya explicación va al principio de la novela y en el capítulo quinto. Más que una novela argumental es una novela de situaciones que se van empujando las unas y las otras y de personajes que alternativamente se caen y se levantan. La visualización es un tanto cinematográfica. Por eso se llama una función que es como antes le llamaban, se decía la función del cine, la función del circo"(Carías, M.: 1984)

El título de la novela puede traducirse entonces como un espectáculo (una función o presentación) de móviles (situaciones que van cambiando o girando sobre sí mismas) y tentetiesos (personajes que suben y bajan en el escenario para dar paso a otros dejando en el aire sólo sus palabras).

La idea de los móviles, sin embargo, conecta con la que puede ser la propuesta interpretativa más penetrante de la novela. Esto en el sentido de que los móviles no sólo habilitan la mecánica compositiva del texto sino que erigen una imagen que interpreta el significado humano del acontecer. Como se verá más adelante, la novela juega con la idea de que en la ciudad no pasa nada, como ocurre con los móviles que parece que no se mueven, y, sin embargo, se mueven. Es una especie de metáfora que permite concebir la experiencia del devenir que puedan tener los habitantes de esa ciudad.

Dorfles señala que los móviles de Calder trascendieron la representación figurativa de la realidad (las representaciones antropomórficas o zoomórficas de la escultura tradicional) para aproximarse al reconocimiento de las estructuras y los ritmos del movimiento (117). Lo que Calder logra según Dorfles es que se concentre la atención en el movimiento mismo: "...una especie de vibración misteriosa recorre estos cuerpos, desde las esferillas blancas y negras que aparecen más livianas todavía en lo más alto de las tenues antenas metálicas, hasta las gruesas y ásperas láminas de acero cargadas de fuerza de gravedad, y que, sin embargo, se mueven por un soplo" (118). En este sentido la novela estaría convocando y al mismo tiempo rebatiendo esa impresión de inmovilidad que podría ser característica de la experiencia de la ciudad.

Otro elemento al que se refieren los críticos para entender la novela es al lenguaje. En la entrevista citada, a una pregunta sobre la peculiar construcción verbal de la novela, el autor contestó que su lenguaje y arquitectura venían en cierta manera determinados por la realidad que buscaba. "El lenguaje de la novela se va generando por una especie de asociación de ideas que toman forma de palabras y de situaciones que remiten a otras situaciones, de ahí la frecuente yuxtaposición. Es 
algo que está también en nuestra manera de hablar, al menos de muchas personas que pasan de un tema otro; la realidad conversacional es más cantinflesca de lo que parece. Además, cada personaje o núcleo de personajes tienen un lenguaje que los identifica, que es recurrente y acumulativo" (Carías, M.: 1984).

Una función comparte con otras novelas del postboom latinoamericano la apertura del texto a los discursos sociales que inundan las obras como desbordan las realidades cotidianas. En la tradición joyceana que habían puesto al día las obras de Cortázar (Rayuela) o de Cabrera Infante (Tres tristes tigres) entre otros, estas novelas recurrieron al modelo de lo que se ha llamado de forma inexacta novelas de lenguaje. (En Centroamérica escribieron bajo esta influencia Carmen Naranjo Diario de una multitud (1974), y el citado Arturo Arias Itzam Na (1981) y Jaguar en llamas (1989).

Angela Dellpiane destacó el hecho de que los autores de estas novelas dejan de entender el lenguaje como instrumento y medio de expresión. "Lo aceptan como una especie de material. Para ellos lo esencial es el lenguaje mismo. Escribir no es la voluntad de comunicar una información disponible sino el proyecto de explorar el lenguaje entendido como un espacio particular" (67-68). Esta exploración del lenguaje puede cobrar el carácter de un acto de conocimiento y en este sentido ser congruente con el vanguardismo literario de Una función. Dice Dellpiane:

"La novela se vuelve una voz, los personajes no existen por sí mismos sino por lo que dicen. Son discurso. El mundo objetivo desaparece... la única realidad es la del discurso del hombre sin el cual ese mundo no existe. La sociedad no es... un hecho biológico, histórico o espiritual sino un lenguaje o superposición de lenguaje. Descifrar estos lenguajes es llegar a comprender las sociedades más diversas, desde las más arcaicas hasta las más modernas"(67-68).

Pero estas novelas también pueden invocar un lenguaje autorreferente, en el sentido de remitir a sí mismo, al simple juego de las palabras o a sus resonancias afectivas o poéticas. Son novelas, dice Dellpiane de la "pura y simple manifestación de un lenguaje que no tiene otra ley que afirmar su existencia, que no hace sino doblarse sobre sí mismo como si su discurso no pudiera tener por contenido más que comentar su propia forma, o bien, que busca encontrar en el acto de la escritura la esencia de toda obra literaria" (66). Jameson encuentra distintivo de la posmodernidad esta inclinación por una textualidad que se cierra sobre sí misma, sobre sus significantes, lo que encuentra propio de una estética de la superficie carente de profundidad típica de los tiempos actuales (198). 
Una función, siendo una novela de lenguaje, no parece autorreferente en el sentido de que los múltiples discursos que convoca arrastran las realidades y los modos de pensar de sus personajes. Está construida efectivamente como una novela polifónica (alejada de las formas simples y unitarias de representación de la novela que expresaba el punto de vista único de un autor autosuficiente) y se complace efectivamente con los juegos de palabras y las ocurrencias verbales de sus personajes 0 de las hablas de la ciudad. Pero esta polifonía es una forma de exploración atenta de los tejidos sociales, lo que aporta es la multiplicidad de puntos de vista y de vivencias que constituyen en un momento cualquiera a la ciudad. Es una especie de rompecabezas de voces y la apuesta por la posibilidad de reconocer sus significados más allá de su caos aparente. En este sentido la novela siendo un juego, es el de intentar reconocer la múltiple unidad y multidemensionalidad de la ciudad.

La crítica quizás en su afán por destacar el carácter "lingüístico" e innovador de Una función ha restado importancia al papel de los personajes y del argumento en su construcción. Arturo Arias al señalar que se trata de una novela de voces confrontada a los modelos de la novela decimonónica expresaba que "no tiene ni movimiento de trama ni personajes redondamente delineados" (186), y Helen Umaña señalaba que la novela "deja de lado el interés por hechos relevantes 0 inusitados y la descripción directa (y ya digerida) de los personajes" (253). Pero si bien es cierto que interesan poco los atractivos de excepcionalidad de la trama y de que no se extiende en la singularización de los personajes, también es cierto que la novela se construye gracias a esos personajes y que su trama no siendo unilineal y basándose más en situaciones, es rica precisamente por ser múltiple y compleja. En este sentido los personajes y los hilos argumentales no desaparecen (sumiendo la novela en una masa informe de discursos) sino que se generan y se enlazan en formas inusitadas.

Dentro del aparente caos narrativo entonces, hay unas ciertas relaciones que pueden observarse y que conforman la arquitectura de la novela. Comienza con una fiesta frívola y de sexuales escarceos como suelen serlo, pero es la fiesta de David un comunista (del que después sabremos que aunque un poco irresponsable organiza un valiente periódico que es saboteado por los testaferros del status quo). Sigue a ello un largo fin de semana de la ciudad (en el que se sorprende a los distintos personajes en los mercados, en el cementerio, en la iglesia, en los estadios deportivos o en la intimidad de sus hogares. La multitud de personajes y situaciones contribuyen a dar una imagen multifacética de una ciudad que reúne al mismo tiempo elementos tradicionales y modernos, religiosos y sacrílegos, chocarreros e idealistas. De pronto ocurren hechos insólitos en un internado de señoritas (es 
descubierto un feto muerto, se provoca un incendio) y sabemos que algo anda mal o se descompone en el edificio de las honorables instituciones de educación. En efecto, al medio de la novela se desencadenan unas violentas manifestaciones estudiantiles y magisteriales (que pueden corresponderse con las que efectivamente ocurrieron en Tegucigalpa en 1969) que son reprimidas y disueltas sin mayores consecuencias. Entonces pudo verse a una venerable profesora dándole escobazos a un tanque militar, pero pudo conocerse también un enigmático personaje Pujol, un estudiante revolucionario que es golpeado en la manifestación y que antes de desaparecer anuncia que volverá. Efectivamente no ha pasado nada, pero algo está pasando y puede pasar (desde un cierto ángulo los hechos pueden ser interpretados como los conocidos movimientos estudiantiles que anunciaron los procesos revolucionarios posteriores en la región). Casi al mismo tiempo, la ciudad es conmovida por otro fenómeno, ahora natural: caen lluvias torrenciales y crecen los ríos provocando graves derrumbes, inundaciones y desplazamientos de damnificados (fenómeno bien conocido por los tegucigalpenses que hace pensar en la recurrencia cíclica de la historia). La naturaleza como la historia esconde resortes profundos que normalmente pasan desapercibidos pero que en un momento se manifiestan (o vuelven a manifestarse) avasallando la vida humana. Pasados los momentos de conmoción hay paseos por la ciudad que permiten incorporar su aspecto físico, sus vistas y paisajes, sus edificios y parques. Al final la novela termina con otra fiesta, ahora en casa de Julia que celebra su nuevo ascenso a funcionaria del Ministerio de Educación. De este modo hay una cierta circularidad que parece volver al mismo punto de arranque, aunque bien visto algunas cosas parecen haber cambiado.

Nunca llega a tenerse un discurrir ordenado de los acontecimientos sino en cada momento una anarquía de voces que los revela, como una ciudadela de Babel en la que todos hablarán a un mismo tiempo. No otra podría ser la imagen totalizadora de un instante en la historia de la ciudad como se propone la novela. $Y$ en esto descansa una de sus premisas principales, en asumir el instante como una convergencia simultánea de acciones y de discursos que lo interpretan. Una misma acción es presentada desde distintos puntos de vista o en un mismo pasaje ocurren distintos hechos o hablan distintos personajes de cosas diferentes. De este modo la simultaneidad se propone como estructura del acontecimiento histórico, lo que contribuye a la imagen confusa y cómica de la realidad que prevalece.

No puede perderse de vista que el novelista es un historiador de profesión que en cierto modo reacciona frente al prejuicio (propio de los habitantes de una ciudad provinciana) de que ahí no pasa nada (de ahí los títulos de los capítulos: "No pasa nada", "Son imaginaciones", etc.). Como se dijo antes, la novela lidia con las 
ilusiones de la inmovilidad y el movimiento como los dilemas propios de una cierta conciencia del devenir. Por una parte, la novela muestra que en cada momento ocurren muchas cosas pero también que son aparentemente triviales o que pueden repetirse cíclicamente. Por otro, el que quizás una vocación más atenta podría revelar que tras el barullo superficial se van gestando procesos más profundos que anticipan o pueden desembocar en rupturas o dar a luz hechos históricos enteros.

"La novela -dice el autor- reacciona primordialmente contra una realidad circular. El móbil del capítulo 6 yo lo dibujé en forma de círculo pero como que hubo dificultades de impresión, digamos como una guirnalda. Todo el capítulo 4, sin embargo, aunque se llama 'no pasó nada', es una especie de aviso de que algo puede pasar'. La búsqueda es siempre la de dominar la realidad en que vivimos, plasmarla, y de paso a nosotros mismos con ella. Búsqueda de identidad y permanencia" (Carías, M., 1984).

Más que confusión que equivale a nada, la novela busca "plasmar" una realidad compleja, y más que rendirse ante ella la novela invita a "dominarla" a seguir sus múltiples y huidizos hilos. Con suficiente tesón sería posible seguir las trayectorias de los personajes y situaciones y armar al menos algunas partes del descomunal rompecabezas que con suspicacia burlona ha propuesto el autor.

El fino entramado de instantáneas recuerda inevitablemente a Joyce. La mano femenina que entrega una limosna y que más tarde resulta la de la propia Molly Bloom. No escapa el sentido divertido con que se incorporan estos juegos, pero igual que en el Ulises todo forma parte de una especie de homenaje a la ciudad puesto en las claves de un juego críptico (50).

Un cursi y extenso diálogo de alrededor de tres páginas (13-16) en el que una intrigante madre presiona a su hija a que confiese su adulterio, no podrá ser entendido sino más adelante cuando unas frases sueltas revelen que se trataba de una telenovela (26 y 221). En la página 4 EI Chichí, que es uno de los niños pobres de la ciudad y todavía un tierno infante, lo vemos subiendo con dificultad unos terraplenes a la orilla del río y sólo en la página 201 sabremos que está salvándose de los derrumbes del día de la inundación. En la página 23 Eugenia, la portera del internado de señoritas, golpea a "un mocoso cipote" con un martillo y sólo en la 185 se sabrá que ha sido a El Mocos, otro de los niños pedigüeños, y que además fue esa misma portera quien enterró al feto muerto descubierto en el digno plantel.

Reuniendo las distintas informaciones Róger Martínez estableció un inventario de personajes que intervienen en las acciones y que reunió en grupos por afinidades. 
Así David, Amapola, Julia, Anita, Víctor Hugo, Margarita María, Emilia, Melba y El Mono Talavera representan a las clases medias cuyas acciones y puntos de vista predominan en la narración. La China y Viena la Profunda (la primera prostituta y la segunda adivinadora o pitonisa) y El Chichí, El Negro y El Mocos (que son los niños de la calle), representan a los marginados aunque con acentos diferentes. El Padre Gaíl (párroco de la iglesia), Mirna, Sofía Rita y Moncha Fiallos (las feligresas más o menos beatas) representan al sector religioso más tradicional. Alba Luz, Adela y las otras maestras son afines a este grupo aunque representan propiamente al sector más tradicional de las instituciones educativas. En contraste el joven Pujol, Enrique, Antonia, Gladis y otros anónimos estudiantes y líderes magisteriales que protagonizan las huelgas y disturbios representan la vanguardia juvenil revolucionaria que surge de los mismos centros educativos. Doña Lina Girbal, Rufo, Alma Leticia y El Ingeniero representan a las clases altas, mientras el Capitán Améndola representa al mismo cuerpo militar del que proviene. Finalmente de extracción popular pero instrumentalizados por las clases altas son Mario Rolando (que hace de testaferrro de los militares) y su novia Berenice (que es una sirvienta típica de las clases altas) (Martínez, R. 1984).

De estos personajes es posible destacar algunos cuyos perfiles resultan importantes en la construcción de la novela. Así David, que sin ser protagonista es uno de los personajes principales, además de ser comunista es profesor de moral y cívica, y sostiene amoríos extramaritales no sólo con Julia sino con Antonia una de sus alumnas. En algún momento de la novela David junto con otros amigos de izquierda deciden que deben organizarse y hacer algo. A expensas de Rufo, el amigo rico, montan una editorial, una librería, publican el periódico y de alguna forma participan en las huelgas. El sabotaje del periódico por parte de los agentes de la represión parece desanimar a David quien al final de la novela decide retirarse a pasar los fines de semana en una finca que tiene en Miramesí.

Julia tiene una vida sexual desordenada que aprovecha para ascender en su carrera profesional aunque con disgusto. Tiene una hija a la que quiere mucho y que se llama Elsie, y resulta involuntariamente embaraza por David. Julia se practica un peligroso aborto que le provoca graves hemorragias durante los días de los derrumbes y la inundación pero sobrevive. Al final con los beneficios de su nuevo cargo en el Ministerio de Educación ha comprado una casa en la Urbanización de El Ingeniero.

El Ingeniero está casado con Sofía Rita, mujer devota que pesa más de doscientas libras, y se ha ganado la lotería con lo que construye la urbanización. Es un hombre emprendedor (furibundo defensor del pragmatismo norteamericano) y parroquiano 
de burdeles (se hace informar por los niños de la calle de las faenas de las prostitutas y planea con otro personaje construir una cadena de estos negocios). En un momento dado se ha conseguido como amante a Margarita María una codiciada joven del grupo de amigos de clase media. Al final El Ingeniero muere de un cáncer 0 de mucho comer y Margarita María llorará por él.

Como puede apreciarse los personajes funcionan como engarces de las situaciones que va desenvolviendo la novela. De hecho, como señala la crítica, la vida interior de los mismos interesa menos que su representatividad social, pero las pinceladas psicológicas que sobre algunos de ellos se ofrecen no sólo los distinguen de una tropa amorfa sino que apuntan hacia historias no contadas. La gran historia, parece sugerir la novela, si es que existe se construye sobre las evoluciones de las ínfimas historias personales.

Amapola Marín, cuyo nombre como el de la mayoría de personajes se ve acompañado siempre de un epíteto burlesco ('Rúbrica y firma'), es una atareada escritora obsesionada con el plagio, que al final extrañamente protegerá al joven Pujol en su huida. Víctor Hugo (cuyo capcioso epíteto 'Torvic Lerocu' indica que es homosexual) le hace la corte a Anita, la esposa de David, a quien enseña a tocar guitarra. En realidad Víctor Hugo es un personaje solapado, pues es agente de las fuerzas de contrainsurgencia que junto con otros villanos de este tipo (Marco Albino, Teto, Lolo, El Gringo Yef y Victoriano) sabotearán la manifestación haciendo actos vandálicos. Al final se le verá apaleando sin motivo a uno de los niños de la calle El Colochosón que es Negro.

Danilo López Brizuela es otro interesante pero sombrío personaje que atraviesa la novela. Marcado por el vandalismo hecho a la tumba de su padre por los gobiernistas, es un declarado comunista cuyas ideas políticas, sin embargo, son del todo líricas o disparatadas. Acaricia la idea, por ejemplo, de una manifestación de protesta de largos kilómetros que protagonizaran las vendedoras de flores de Santa Lucía. También añora a su novia de juventud Alma Leticia, la mujer de Rufo el mecenas del periódico, con la que se encuentra muchas veces a leer poemas en el parque La Concordia. En la práctica se la pasa el tiempo bebiendo en la cantina El Teñidero con su amigo El Mono Talavera otro periodista. Al final López Brizuela decide no volver a visitar la tumba de su padre. Una lectura aun más acuciosa podría hacer ver que aunque la novela presenta núcleos y grupos sociales en movimiento, sus evoluciones en realidad se encuentran tejidas de finas historias individuales, de modo que para cada personaje tal vez podría encontrarse su propia historia con principio nudo y desenlace. Al menos esto es lo que mueve a pensar el que puedan reconocerse trayectorias de personajes a penas mencionados como El Padre 
Ignacio que al final de la novela dejará los hábitos para casarse con la madre de Rodimiro, El Chichí, y ejercerá el oficio de taxista. O el caso de El Mocos ("cara de estar llorando") que será colgado en el tabanco de una casucha por Eugenia (la portera del internado) por haber descubierto el feto. Al final la propia Eugenia se compadecerá del niño y lo liberará de tan grave trance. Un motivo de la discursivización que echa a andar la novela y que quizás le da unidad a sus múltiples hilos, es el de operar la escritura como una especie de registro de la memoria anecdótica, verbal, e incluso visual de la ciudad. Las múltiples historias en efecto no articulan una trama propiamente dicha como en la novela tradicional sino que pueblan la novela recreando esa atmósfera de vivencias que a la postre puede constituir la sustancia de la experiencia histórica. Así se explica que la trayectoria de muchos personajes no conduzca aparentemente a ninguna parte sino a esto: a una presencia humana dispersa y apenas perceptible que quizás fuera la imagen más verosímil de la ciudad.

Algo parecido pasa con las instantáneas visuales de los espacios físicos y los paisajes que la novela aporta. Rara vez hay descripciones extensas pero en ocasiones (sobre todo en los últimos capítulos) atraviesan vistas que inmediatamente incitan la memoria de lugares, construcciones, o rincones característicos de la ciudad. El cementerio, el río, los parques, las callejuelas empedradas, las escaleras que suben por los barrios empinados, los balcones, las flores, los paisajes montañosos, etc. Puede observarse que es gracias a una suerte de asociaciones inconscientes que estos datos consiguen despertar memorias vivenciales de la ciudad en la medida en que la materialidad por sí misma está desprovista de sentido.

\section{CONCLUSIONES}

Evidentemente como sostiene la crítica este texto no puede leerse como una novela convencional, pero se perdería de vista algo muy importante de su propuesta si no se considera que la escritura está tratando de procesar intelectualmente una serie de vivencias de la ciudad. La escritura hace presentes esas vivencias como fragmentos de experiencia que sólo en su reunión dan una especie de atisbo de esa visión de conjunto que se anhela.

En este sentido, el texto más bien habría que leerlo como una forma de participar en el acto creativo y perceptivo que despliega, como una forma de complicidad con la elaboración de esos datos de experiencia (memoria de impresiones y de microhistorias), que de algún modo se sabe que constituyen ese espacio humano que llamamos Tegucigalpa. 


\section{REFERENCIAS BIBLIOGRÁFICAS}

Arias, Arturo. 1998. "Pactos retóricos, concierto de voces barrocas". En Gestos ceremoniales. Narrativa centroamericana 1960-1990. Guatemala. Artemio Edinter.

Bermúdez, Hernán Antonio.2007. "La novela de Tegucigalpa” En Afinidades. (Notas y ensayos críticos). Tegucigalpa. Editorial Secretaría de Cultura Artes y Deportes. Páginas 131-134.

Calinescu, Matei. 1987. Five Faces of Modernity. Modernism, Avant-Garde, Decadence, Kitsch, Postmodernism. Durham. Duke University Press.

Carías, Marcos. 1980. Una función con móbiles y tentetiesos. Tegucigalpa. Guaymuras.

Carías, Marcos. 1985. Entrevista. Tegucigalpa. Inédita.

De Micheli, Mario. 1988. Las vanguardias artísticas del siglo XX. Madrid. Alianza. Dellepiane, Ángela B. 1972. "La novela del lenguaje" en Bleznick, Donald W. (Comp.) Variaciones interpretativas en torno a la nueva narrativa hispanoamericana. Santiago de Chile. Helmy Giacoman Editor.

Dorfles, Gillo. 1963. El devenir de las artes. México. Fondo de Cultura Económica. Jameson, Frederic. 2000. "Posmodernism, or The Cultural Logic of Late Capitalism". En Hardt, Michael; Kathi Weeks (eds.) The Jameson Reader. Massachussetts, EEUU. Blackwell Publishers.

Lukacs, Georg. 1962. Teoría de la novela. Buenos Aires. Ediciones Siglo Veinte.

Lukacs, Georg. 1966. La novela histórica. México. Biblioteca Era.

Lyotard, Jean Francoise. 2004. “¿Qué era la posmodernidad?” en El debate modernidad-posmodernidad. Nicolas Casullo editor. Buenos Aires. Retórica. Páginas 65-74.

Martínez, Róger. 1985. Los personajes en Una función con móbiles y tentetiesos. Tegucigalpa. Inédito.

Torres, Claudia. (s.a.) Posmodernidad en la novela Una función con móbiles y tentetiesos. University of Austin. Texas. (Manuscrito).

Umaña, Helen. 1986. "El afán totalizador en Una función con móbiles y tentetiesos". En Literatura hondureña contemporánea. Ensayos. Tegucigalpa. Guaymuras. 